\title{
El espectador emancipado
}

JaCQUES RANCIÈRE

Jacques Rancière, Manantial, 2010, Buenos Aires, 131 pág.,

ISBN 978-987-500-137-4

a lectura de El maestro ignorante es requisito indispensable para Lcomenzar la lectura de El espectador emancipado. En el primer texto, Rancière comienza a exponer una serie de propuestas en torno a una nueva concepción de alumno. Estas ideas están inspiradas en las teorías del pedagogo francés Jean Jacotot, y tienen como centro el concepto de igualdad y la propuesta de una educación para la emancipación.

Rancière quedará gratamente sorprendido con el trabajo de Jacotot, quien propone que el maestro no tiene que estar en una posición de ventaja, y traspasar su saber al alumno; por el contrario, el alumno debe llegar a aprender lo que el maestro no sabe. Este ejercicio de Jacotot despierta en Rancière la idea de un espectador emancipado y la descripción de un particular proceso de emancipación en lo que respecta al arte. Rancière extrapolará la figura del alumno en la del espectador, pues, ninguna de estas dos figuras debe seguir en un rol pasivo. Espectador y alumno se relacionan en la posición de desventaja que tienen, el alumno ante su maestro y el espectador ante el artista. Para Jacotot, tal como para Rancière, ellos deben dejar de ser sólo receptores; pues se pretende que sean ellos quienes se hagan cargo y en tal proceso transformen aquello que entrega el maestro y también el artista a cada uno de sus receptores, alumno y espectador, respectivamente. Del mismo modo que el maestro no enseña lo que sabe al alumno, el artista no pretende instruir a su espectador, este maestro al que alude Jacotot, el maestro ignorante no enseña su saber, por lo tanto aquello que el alumno aprende es algo que ni el mismo maestro sabe. He aquí la paradoja del maestro ignorante.

El espectador emancipado presentará un cierto tipo de relación entre artista y espectador, tal como El maestro ignorante presentaba al maes- 
tro y al alumno. Para esto prestará especial atención al escenario del teatro. Rancière considera el teatro como el espacio comunitario por excelencia; en palabras del mismo autor, el teatro es por sí mismo un lugar comunitario.

La emancipación sólo puede ser llevada a cabo por sujetos, vale decir, que en ningún caso lo que sucede en el alumno, o en el espectador, es resultado puramente de las intenciones del maestro o del autor. Hablamos por tanto, de un espectador a cargo de producir sus propias transformaciones, un actor consciente de sus potencialidades.

A Rancière le interesa el espectador de teatro, y se centrará en él, pues el teatro es la mejor representación de la sociedad en que vivimos, en la cual nos movemos. La posición de espectador de teatro es bastante sugerente, pues él se encuentra sentado frente al escenario tal como un espectador de la comunidad. En cierto sentido, todos somos espectadores, y el teatro permite componer, o recomponer. La obra, en tal sentido no sólo se observa, sino que se constituye a partir del espectador.

A lo largo de los textos estéticos de Rancière vemos una crítica constante a la figura del teatro; al mismo tiempo, éste será el lugar que más le acomoda para hablar de las artes. En estas constantes críticas, Rancière establecerá una cierta reestructuración en la forma de pensar el teatro, que consiste en dejar de verlo como espectáculo -relación de observación-y situarlo como un espacio de visibilidad de la sociedad, en que cada uno de los sujetos participantes de la comunidad se hace parte de su situación, y de cómo pueden participar de ella.

Dentro del proceso de emancipación de los nuevos espectadores del arte, está el poder de asociar y disociar, como una nueva capacidad que hace a cada uno igual a otro. Rancière muestra una preferencia por autores como Artaud o Brecht, que según su perspectiva, no intentan entregar a través de su obra una suerte de conocimiento. En este caso, el artista no intenta instruir al espectador, al igual que en el caso del alumno, lo que él aprende es lo que el maestro no sabe. 
En contraposición a esta forma de ver, está la lógica embrutecedora, que se gesta justamente cuando el alumno debe aprender lo que el maestro le enseña, mientras en el caso del espectador, él debe ver aquello que el artista quiere que vea; en este caso lo que el director teatral le hace ver. La lógica embrutecedora, por tanto, es aquella que se mueve dentro de unas relaciones de causa y efecto a la que Rancière, claro está, pretende renunciar.

A diferencia de lo que alguna vez pretendieron los artistas de vanguardia, Rancière piensa a este nuevo artista no como el maestro que educa a sus alumnos, en este caso el artista que educa a sus espectadores. Esto se debe a que no hay nada que enseñar: el artista no se encuentra en una posición de ventaja sobre su espectador, y el artista está consciente de ello. Este "nuevo" artista del que habla Rancière pretende proponer una relación con la realidad y con la ficción, y que el espectador sea capaz de aprehender su obra, tomando decisiones en torno a ella. Efectivamente, no existe una diferencia entre el artista y el espectador, ambos se encuentran participando de la obra de la misma manera.

Jacotot dirá que en contraposición al maestro ignorante se encuentra el pedagogo embrutecedor, quien le enseña a su alumno aquello que él cree saber. Dentro de esta misma lógica, se encuentra el artista que quiere hacer que sus espectadores vean y sientan cosas determinadas por él. Es por ese artista y por el espectador pasivo que él mismo ha generado que Rancière construye la nueva idea de un espectador emancipado, que es capaz de ver y al mismo tiempo de transmutar, si así lo desea, aquello que se presenta frente a sus ojos. La lógica embrutecedora es la lógica que maneja el artista-maestro, y al mismo tiempo la traspasa a su espectador, embruteciéndolo, haciendo ver a éste lo que el autor de la obra, el artista, quiere que vea, convirtiéndolo así en un espectador inalterable, en un mirón.

Otro concepto ranceriano significativo, dentro de este escenario, es el concepto de igualdad; que está íntimamente ligado al concepto de emancipación. Pues la emancipación tiene como finalidad la igualdad 
de los sujetos dentro de la comunidad. Es relevante destacar que la emancipación, vista por Rancière, toma distancia del concepto más tradicional de ella; pues, para el francés, la emancipación no es un proceso exógeno. Al contrario, la emancipación sólo puede ser llevada a cabo por cada uno de los sujetos. Rancière no está de acuerdo con las perspectivas de emancipación que desestiman a los sujetos como tales, en su singularidad. No entiende el proceso emancipatorio como un proceso que se desarrolla en masa, sino como un proceso que pertenece a "sujetos" que interactúan.

Por medio de la emancipación es posible lograr la igualdad de cada uno de los sujetos dentro de la comunidad. Cada sujeto sólo puede emanciparse por sí mismo. Estas son las mismas condiciones que luego le servirán a Rancière para seguir desarrollando las perspectivas de una comunidad camino a la igualdad, que propone bajo la idea de un reparto de lo sensible. Por medio del reparto de lo sensible se pretende llegar al orden que propone dar el autor a la comunidad, o sea, este reparto funciona como el instrumento que llevará a cabo una nueva organización, una redistribución. Desde tal perspectiva, no hay que entender política y arte como esferas separadas; sino como actividades que convergen en la reconfiguración material de la comunidad. El trabajo del arte queda así expuesto como una tarea de intervención sobre el reparto de lo sensible, es decir, sobre la distribución de lo común en la sociedad, en quienes participan en ella, en los grados y modalidades de tal participación.

Siguiendo en el lenguaje ranceriano, el espectador emancipado será el espectador de un tipo de arte especial; este será el arte crítico. Cuando Rancière habla de arte crítico no se referirá al arte de alguna época en específico, sino que este arte se constituye desde un espectador que lo mira, pero este espectador no es cualquier espectador, sino un espectador emancipado. Este espectador es capaz de transformar aquello que ve, convirtiéndose así, en actor; deja ese sitio de pasividad aquejado de atontamiento y embrutecimiento. Efectivamente, no es que el arte crítico necesite de un espectador emancipado; sino que, aquello que 
hace que el arte se transforme en arte crítico es ese espectador que está frente a él. Es por ello, que cualquier arte, de cualquier época, puede transformarse en arte crítico en la medida que está siendo constituido por un espectador emancipado. Es relevante subrayar la presencia de tal espectador para hacer un cambio en el arte, y así mismo en la comunidad. Sin este espectador el arte sigue siendo un arte para un público adormecido. Ahora bien, el espectador tiene una presencia activa que hace de su experiencia estética un medio para actuar y cambiar su contexto inmediato. Desde el arte crítico el espectador es capaz de cuestionar aquello que ve. El emancipado está conciente de quien es, esto hace que incluso pueda asumir sin turbaciones el orden social como pura convención, e incluso la posición de "superiores" que otros aparentemente detentan; pues sabe que en estricto rigor se trata de una ficción. Sin embargo, el embrutecido no teme a nada; al contrario del emancipado, jamás sabrá aquello.

Rancière en El espectador emancipado nos presenta una serie de instrumentos más, para comprender su particular propuesta en torno a la estética, es decir, a la construcción de un reparto de lo sensible: es el espectador emancipado el sujeto -o un tipo de subjetividadcapaz de constituir un cambio y la transformación necesaria para la comunidad.

Paula Poblete Vargas. Licenciada en Filosofía. ARCIS. 